\title{
Pharmacokinetics and tolerability of eletriptan hydrobromide in healthy Korean subjects
}

This article was published in the following Dove Press journal:

Drug Design, Development and Therapy

\author{
Yu Kyong Kim' \\ Kwang-Hee Shin ${ }^{2}$ \\ Jeffrey Alderman ${ }^{3}$ \\ Kyung-Sang $\mathrm{Yu}^{\prime}$ \\ In-Jin Jang' \\ SeungHwan Lee' \\ 'Department of Clinical Pharmacology \\ and Therapeutics, Seoul National \\ University College of Medicine and \\ Hospital, Seoul, Republic of Korea; \\ ${ }^{2}$ College of Pharmacy, Kyungpook \\ National University, Daegu, Republic \\ of Korea; ${ }^{3}$ Pfizer, Inc., New York, \\ NY, USA
}

\begin{abstract}
Background: Migraine is one of the most common headache disorders that greatly affect the quality of life. Selective serotonin (5-HT) receptor agonists such as triptamine-based drugs called triptans are used for treatment of migraine.

Purpose: This study aimed to evaluate the pharmacokinetic (PK) and tolerability profiles of eletriptan hydrobromide (eletriptan $\mathrm{HBr}$ ), a selective 5-hydroxytryptamine (also known as serotonin) $1 \mathrm{~B} / 1 \mathrm{D}$ receptor agonist, in Koreans and compare the results to those observed in non-Koreans in a previously published study.
\end{abstract}

Patients and methods: A randomized, open-label, single, and repeated-dose study was conducted in 16 healthy Korean male subjects using a four-treatment, four-period, and four-sequence crossover design (NCT01139515). The subjects received one of the following four treatments in each period: a single dose of 20,40, $80 \mathrm{mg}$ eletriptan $\mathrm{HBr}$ or a repeated oral dose of $40 \mathrm{mg}$ $2 \mathrm{~h}$ apart. Blood samples were collected before and up to $26 \mathrm{~h}$ after dosing for quantification of plasma eletriptan concentration by high-performance liquid chromatography tandem-mass spectrometry. The PK parameters were estimated using noncompartmental methods. Ethnicity differences between Korean and non-Korean subjects were identified using geometric mean ratios and $90 \%$ confidence intervals (CIs) of dose-normalized maximum plasma concentration $\left(\mathrm{C}_{\max }\right)$ and dose-normalized area under the plasma concentration versus time curve from $0 \mathrm{~h}$ to the last measurable concentration $\left(\mathrm{AUC}_{0-t}\right)$.

Results: After single-dose administration of eletriptan $\mathrm{HBr}$ to Korean subjects, the mean $\mathrm{C}_{\max }$ and $\mathrm{AUC}_{0-t}$ increased linearly with dose. Comparable total systemic exposures were observed in the $2 \mathrm{~h}$ apart $40 \mathrm{mg}$ repeated and single $80 \mathrm{mg}$ dose. The geometric mean ratios ( $90 \% \mathrm{CIs}$ ) of the dose-normalized $\mathrm{C}_{\max }$ and $\mathrm{AUC}_{0-\mathrm{t}}$ of Korean subjects were similar to those of non-Korean subjects reported in the literature. The adverse events observed were transient and mild in severity.

Conclusion: Eletriptan $\mathrm{HBr}$ showed linear PK and was well tolerated in Korean subjects. The PK and tolerability of eletriptan HBr did not differ between Korean and non-Korean subjects.

Keywords: pharmacokinetics, migraine, eletriptan hydrobromide, Korean subjects

\section{Introduction}

Migraine is one of the most common headache disorders that greatly affect the quality of life. The prevalence of migraine is relatively high: about $15 \%-18 \%$ in women and $6 \%$ in men. ${ }^{1}$ For effective treatment of migraine, it is necessary to understand its pathophysiology. A proposed theory on migraine pathophysiology is the neurovascular theory, which is characterized by a cascade of events involving various combinations of neurologic, autonomic, and gastrointestinal changes. ${ }^{2}$ Selective serotonin (5-HT) receptor agonists can arrest the pathophysiological cascade; therefore, various agonists, which are collectively called triptans, have been developed for clinical use. 
According to the neurovascular theory described above, triptamine-based drugs such as triptans elicit their effects on migraine patients through intracranial vasoconstriction, in addition to the inhibition of neuropeptide release, ${ }^{3}$ which ultimately relieves the acute migraine symptoms. The triptans currently available and widely used for the treatment of acute migraine attacks in Korea are naratriptan, sumatriptan, and zolmitriptan. As a potent and selective 5-HT1B/1D agonist, eletriptan hydrobromide (eletriptan $\mathrm{HBr}$ ) acts selectively on the carotid region of 5-HT receptors ${ }^{4}$ instead of the coronary arteries. ${ }^{5}$ However, the pharmacokinetics (PK) and tolerability profiles of eletriptan $\mathrm{HBr}$ in Koreans were undetermined and not yet approved in Korea. By comparing with the results of a previous head-to-head comparative study with sumatriptan ${ }^{6}$ and double-blind single-attack studies with naratriptan ${ }^{7}$ and zolmitriptan, ${ }^{8}$ eletriptan $\mathrm{HBr}$ was found to show a more rapid onset of efficacy.

Owing to the presence of greater lipophilic characteristics than other triptans, eletriptan $\mathrm{HBr}$ has relatively higher bioavailability $(\sim 50 \%)$ and volume of distribution. The peak plasma concentrations in non-Korean healthy subjects occurred between 1 and $1.5 \mathrm{~h}$ after dosing (time required to reach maximum plasma concentration $\left[\mathrm{T}_{\max }\right]$ ), and in migraine patients with an acute migraine attack, the median $\mathrm{T}_{\text {max }}$ occurred at 2 h. ${ }^{9}$ Approximately $85 \%$ of eletriptan $\mathrm{HBr}$ was protein bound with an elimination half-life $\left(\mathrm{t}_{1 / 2}\right)$ ranging from 4.8 to $7 \mathrm{~h}$ in healthy subjects, and the half-life was unaffected by sex, race, age, or menstrual cycle phases in female subjects. ${ }^{10}$ Only $10 \%$ of eletriptan is cleared through the renal pathway, about $80 \%$ is eliminated via hepatic demethylation by CYP3A4 isoenzyme, and $10 \%$ by CYP2D6. ${ }^{10}$

Eletriptan $\mathrm{HBr}$ is approved in the United States and Japan at recommended single doses of $20,40,80 \mathrm{mg}$ or repeated doses of $40 \mathrm{mg}$ if required, with a maximum daily dose of $80 \mathrm{mg}$. However, the PK and tolerability profiles of eletriptan $\mathrm{HBr}$ in Koreans were undetermined, and the medication is not yet approved in Korea.

We performed a clinical study with the objective of evaluating the $\mathrm{PK}$ and tolerability profiles of eletriptan $\mathrm{HBr}$ in healthy Korean subjects and compared it with those reported previously in non-Koreans. ${ }^{9}$

\section{Methods}

\section{Study drug, ethics approval, and consent to participate}

Eletriptan $\mathrm{HBr} 20 \mathrm{mg}$ as a $20 \mathrm{mg}$ tablet, $40 \mathrm{mg}$ as a $40 \mathrm{mg}$ tablet, and $80 \mathrm{mg}$ as two $40 \mathrm{mg}$ tablets were administered for the assessment of PK and tolerability to healthy Korean subjects who met the inclusion and exclusion criteria of the study. Candidates were considered to be healthy based on clinical laboratory test results and clinical assessments such as physical examination performed at the time of screening. Written informed consent was obtained from all individual participants included in the study prior to screening tests.

The study protocol was reviewed and approved by the Institutional Review Board at Seoul National University Hospital (ClinicalTrials.gov registry no: NCT01139515). This study was conducted at the Clinical Trials Center, Seoul National University Hospital, Seoul, Korea. The study was conducted in accordance with the principles stipulated in the Declaration of Helsinki as amended in 2013 (Fortaleza, Brazil) ${ }^{11}$ and the International Conference on Harmonization Good Clinical Practice Guideline. ${ }^{12}$

\section{Study design}

This study was designed as a randomized, open-label, single and repeated-dose, 4-period, and 4-sequence crossover study. Sixteen subjects between the ages of 18 and 55 years were randomized into four treatment groups; a single oral dose of 20,40 , or $80 \mathrm{mg}$, and a $2 \mathrm{~h}$ apart repeated oral dose of $40 \mathrm{mg}$ of eletriptan $\mathrm{HBr}$ (Figure 1). The subjects had at least a 46-h washout period between the doses in each period. The study drugs were orally administered under fasting conditions, with $240 \mathrm{~mL}$ of water.

All subjects were admitted to the Clinical Trials Center a day before dosing, and they were required to fast for at least $8 \mathrm{~h}$ prior to dosing. During the entire study period, the subjects were restricted from taking any concomitant medication or beverages containing xanthine or alcohol.

For the determination of plasma eletriptan concentrations, blood samples $(6 \mathrm{~mL})$ were serially collected in tubes containing lithium heparin prior to dosing and at $0.5,0.75$, $1,1.5,2,3,4,6,8,10,12,16$, and $24 \mathrm{~h}$ after dosing for the single-dose treatment groups. For the repeated-dose group of $40 \mathrm{mg}$, the blood samples were collected prior to dosing and at $0.5,0.75,1,1.5,2,2.5,2.75,3,3.5,4,5,6,8,10,12$, 14,18 , and $26 \mathrm{~h}$ after dosing. Samples were centrifuged at $1,700 \times g$ for $10 \mathrm{~min}$ at $4^{\circ} \mathrm{C}$. The plasma was separated and stored at $-20^{\circ} \mathrm{C}$ until concentration analysis.

\section{Determination of eletriptan plasma concentration}

Plasma concentrations of eletriptan were assayed by a validated method using high-performance liquid chromatography with mass spectrometry detection. The lower and upper limits of quantification were 0.5 and $250 \mathrm{ng} / \mathrm{mL}$, respectively, 


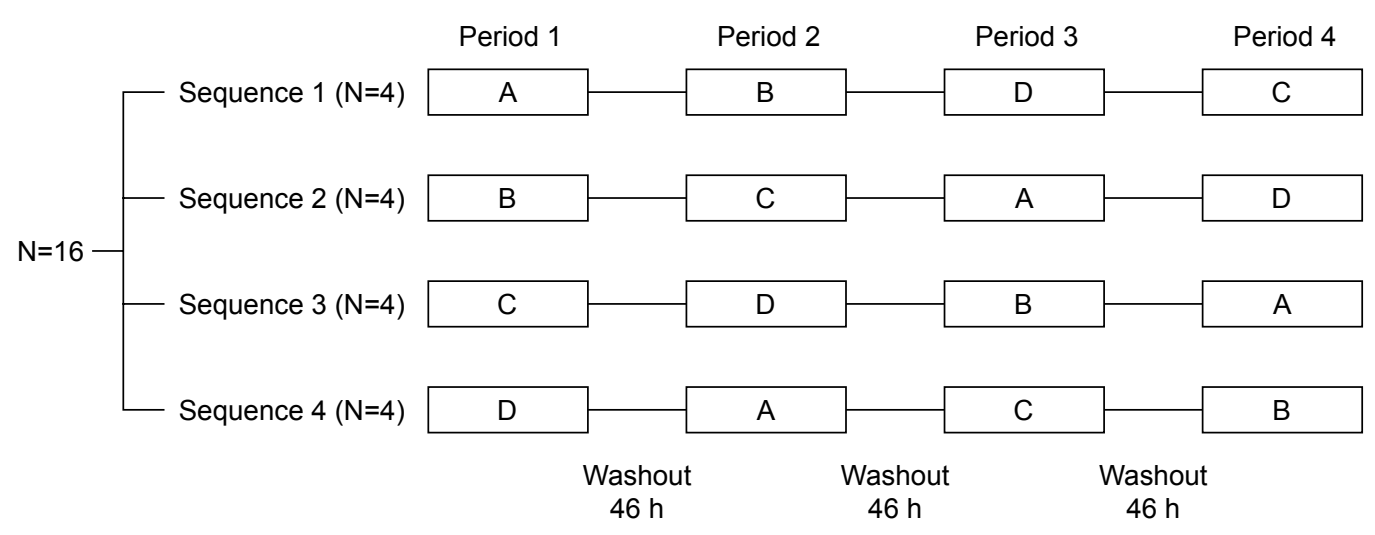

Figure I Study design: (A) one $20 \mathrm{mg}$ eletriptan $\mathrm{HBr}$ tablet, (B) one $40 \mathrm{mg}$ eletriptan $\mathrm{HBr}$ tablet, (C) two $40 \mathrm{mg}$ eletriptan $\mathrm{HBr}$ tablets administered as a single dose (total dose $=80 \mathrm{mg}$ ), (D) two $40 \mathrm{mg}$ eletriptan $\mathrm{HBr}$ tablets administered $2 \mathrm{~h}$ apart (total dose $=80 \mathrm{mg}$ ). Subjects were randomly assigned to one of the indicated crossover treatment sequences (Sequence I-4) on the day of study drug administration ( $0 \mathrm{~d}$ ), and each period was separated by at least $46 \mathrm{~h}$ of washout.

Abbreviation: eletriptan $\mathrm{HBr}$, eletriptan hydrobormide.

and the calibration curve of the method was linear over this range. Where necessary, samples were diluted with normal human plasma to bring the concentration within the calibration range. Calibration standards were prepared by spiking blank plasma samples with known amounts of eletriptan ranging from 0.5 to $250 \mathrm{ng} / \mathrm{mL}$. The accuracy (expressed as the percentage difference from the theoretical concentration) of the quality control samples used during the sample analysis ranged from $-2.0 \%$ to $4.7 \%$ with a precision (expressed as the coefficient of variation) of $\leq 9.7 \%$.

\section{PK evaluation and ethnic comparison}

The plasma concentrations of eletriptan with time after the dose were analyzed. The following PK parameters for each treatment group $(20,40,80 \mathrm{mg}$, and two $40 \mathrm{mg}$ repeated dose, $2 \mathrm{~h}$ apart) were analyzed: maximum plasma concentration $\left(\mathrm{C}_{\max }\right), \mathrm{T}_{\max }$, area under the plasma concentration versus time curve from $0 \mathrm{~h}$ to the last measurable concentration $\left(\mathrm{AUC}_{0-\mathrm{t}}\right.$, where $\mathrm{t}$ is the last time point with a measurable concentration), area under the plasma concentration versus time curve from $0 \mathrm{~h}$ to infinity $\left(\mathrm{AUC}_{0 \text {-inf }}\right)$, and the elimination half-life $\left(\mathrm{t}_{1 / 2}\right)$. The $\mathrm{AUC}_{0-\mathrm{t}}$ was calculated using the linear trapezoidal method. The observed concentrations and times were used to estimate the $\mathrm{C}_{\max }$ and $\mathrm{T}_{\max }$ of eletriptan. $\mathrm{AUC}_{0 \text {-inf }}$ was calculated as $\mathrm{AUC}_{0-\mathrm{t}}+\mathrm{C}_{\mathrm{t}} / \lambda$, where $\mathrm{C}_{\mathrm{t}}$ is the last measured concentration and $\lambda_{z}$ is the elimination rate constant calculated using linear regression of the log-linear portion of the plasma concentration-time curve. The $t_{1 / 2}$ was calculated as $\ln (2) / \lambda_{\mathrm{z}}$. All the PK parameters were estimated using Phoenix ${ }^{\circledR}$ WinNonlin ${ }^{\circledR}$ (version 6.3; Certara USA Inc., Princeton, NJ, USA). For evaluating the dose linearity of eletriptan $\mathrm{HBr}$ in Korean subjects, the dose-normalized mean differences of $\mathrm{C}_{\max }, \mathrm{AUC}_{0-\mathrm{t}}$, and $\mathrm{AUC}_{0-\text { inf }}$ and the corresponding $90 \%$ confidence intervals (CIs) for the differences were exponentiated to provide estimates of the ratio of dose-normalized geometric means and 90\% CIs.

The current PK of eletriptan $\mathrm{HBr}$ in Koreans were compared with the data of non-Koreans published in $2002^{9}$ for an ethnic comparison between the two populations. The PK of eletriptan $\mathrm{HBr}$ for the two populations were compared by calculating the point estimate and $90 \%$ CI of the dosenormalized $\mathrm{C}_{\max }, \mathrm{AUC}_{0-t}$, and $\mathrm{AUC}_{0 \text {-inf }}$ by weighted average pooling method. All statistical analyses were performed using SAS version 9.4 software (SAS Institute Inc., Cary, $\mathrm{NC}, \mathrm{USA}$ ).

\section{Tolerability assessment}

Tolerability assessment, including vital signs (systolic and diastolic blood pressures, pulse rate), physical examination, and adverse events (AEs) were conducted prior to the study drug administration until the completion of the study. The subjects were interviewed during the course of the study for collecting information regarding $\mathrm{AE}$, which were monitored throughout the study by nonleading questioning.

For ethnic comparison, the types, frequency and severity of AEs, and other tolerability parameters including the changes in vital signs were compared between the Korean and non-Korean subjects.

\section{Results Subjects}

Sixteen subjects completed the study and were included in the assessment of PK characteristics and tolerability. The mean \pm standard deviation of age, height, weight, and body mass index were $24.8 \pm 2.9$ years, $172.2 \pm 5.3 \mathrm{~cm}, 65.8 \pm 5.7 \mathrm{~kg}$, and $22.2 \pm 1.8 \mathrm{~kg} / \mathrm{m}^{2}$, respectively. 

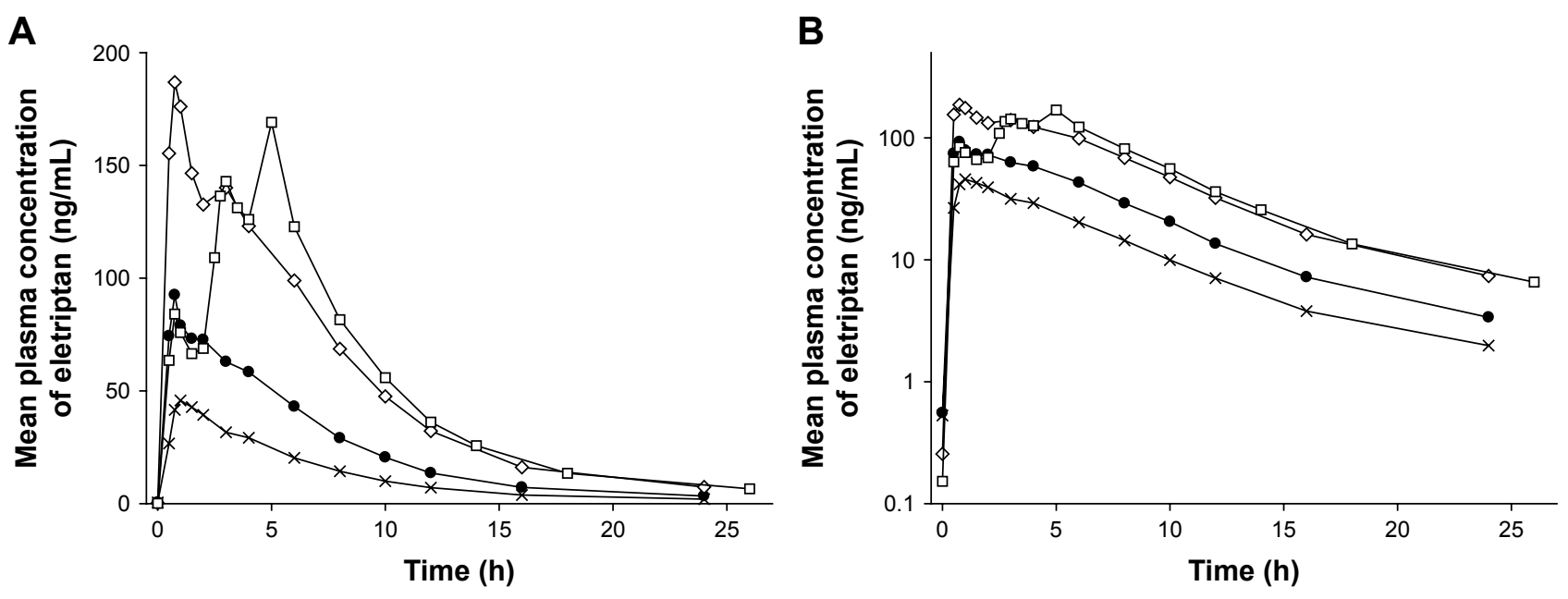

$\rightarrow$ Eletriptan $\mathrm{HBr} 20 \mathrm{mg}(\mathrm{N}=16) \multimap$ Eletriptan $\mathrm{HBr} 40 \mathrm{mg}(\mathrm{N}=16) \multimap$ Eletriptan $\mathrm{HBr} 80 \mathrm{mg}(\mathrm{N}=16)$
$\rightarrow-$ Eletriptan $\mathrm{HBr} 2 \mathrm{~h}$ apart repeated $40 \mathrm{mg}(\mathrm{N}=16)$

Figure 2 Mean plasma concentration versus time curves of eletriptan after single oral doses of $20 \mathrm{mg}(\rightarrow-), 40 \mathrm{mg}(-\bullet), 80 \mathrm{mg}(-\diamond)$, and $2 \mathrm{~h}$ apart repeated $40 \mathrm{mg}(-\square-)$ eletriptan $\mathrm{HBr}$ in healthy Korean subjects; in (A) linear and (B) semi-logarithmic scale $(\mathrm{N}=16)$.

Abbreviation: $\mathrm{HBr}$, hydrobormide.

\section{PK profiles}

The mean plasma eletriptan concentration versus time curves after single oral doses of 20,40,80 $\mathrm{mg}$, and $2 \mathrm{~h}$ apart repeated $40 \mathrm{mg}$ dose of eletriptan $\mathrm{HBr}$ in healthy Korean subjects are presented in Figure 2. The median $\mathrm{T}_{\max }$ values were similar among the single oral doses of eletriptan $\operatorname{HBr}(0.75 \mathrm{~h})$, while the median $\mathrm{T}_{\max }$ for the $2 \mathrm{~h}$ apart repeated $40 \mathrm{mg}$ dose ranged from 0.75 to $5 \mathrm{~h}$ with a median value of $5 \mathrm{~h}$ (Figure 2; Table 1). The $t_{1 / 2}$ was similar for all the four treatment groups, with the mean $\mathrm{t}_{1 / 2}$ values ranging from 4.6 to $4.9 \mathrm{~h}$ (Table 1 ).

Following the single oral doses of eletriptan $\mathrm{HBr}$, the systemic exposure of eletriptan increased in a dose-proportional manner across the dose range of 20-80 mg in healthy Korean subjects (Table 1; Figure 3). This is further supported by the narrow ranges of dose-normalized $\mathrm{C}_{\max }, \mathrm{AUC}_{0-\mathrm{t}}$, and $\mathrm{AUC}_{0 \text {-inf }}$ values: $2.33-2.50 \mathrm{ng} / \mathrm{mL} / \mathrm{mg}, 13.97-15.54 \mathrm{~h} \cdot \mathrm{ng} / \mathrm{mL} / \mathrm{mg}$, and 14.39-16.03 h.ng/mL/mg, respectively.

The point estimates and the $90 \% \mathrm{CI}$ of the dosenormalized $\mathrm{C}_{\max }, \mathrm{AUC}_{0-\mathrm{t}}$, and $\mathrm{AUC}_{0-\text { inf }}$ between Korean and non-Korean subjects were similar (Table 2). This indicates a similar bioavailability of eletriptan $\mathrm{HBr}$ between the two ethnic groups.

\section{Tolerability}

Among the nine cases of AEs reported in the 16 Korean subjects who received the study drug, loose stool, abdominal pain, and headache were considered to be possibly related to the administration of eletriptan $\mathrm{HBr}$. All reported study

Table I PK parameters of eletriptan after single and $2 \mathrm{~h}$ apart repeated oral doses of eletriptan $\mathrm{HBr}$ in healthy Korean subjects ( $\mathrm{N}=\mathrm{I6}$ )

\begin{tabular}{|c|c|c|c|c|}
\hline \multirow[t]{2}{*}{ Parameters } & \multicolumn{4}{|c|}{ Geometric mean (\%CV) } \\
\hline & $20 \mathrm{mg}$ & $40 \mathrm{mg}$ & $80 \mathrm{mg}$ & $40 \mathrm{mg}$ repeated \\
\hline $\mathrm{T}_{\text {max }}(h)^{\mathrm{a}}$ & $0.75(0.50-2.00)$ & $0.75(0.50-4.00)$ & $0.75(0.50-6.00)$ & $5.00(0.75-5.02)$ \\
\hline$t_{1 / 2}(h)$ & $4.92(14)$ & $4.63(10)$ & $4.58(12)$ & $4.75(13)$ \\
\hline $\mathrm{C}_{\max }(\mathrm{ng} / \mathrm{mL})$ & $46.50(39)$ & $94.72(48)$ & $200.10(45)$ & $183.6(29)$ \\
\hline$A \cup C_{0-t}(h \cdot n g / m L)$ & $281.20(43)$ & $558.70(40)$ & $1,243.00(32)$ & I,244.00 (33) \\
\hline$A \cup C_{0-\text { inf }}(\mathrm{h} \cdot \mathrm{ng} / \mathrm{mL})$ & $291.30(45)$ & $575.60(4 I)$ & $1,282.00(32)$ & $1,278.00(33)$ \\
\hline $\mathrm{C}_{\max } /$ dose $(\mathrm{ng} / \mathrm{mL} / \mathrm{mg})$ & $2.30(39)$ & $2.37(48)$ & $2.50(45)$ & - \\
\hline $\mathrm{AUC}_{0-\mathrm{t}} /$ dose $(\mathrm{h} \cdot \mathrm{ng} / \mathrm{mL} / \mathrm{mg})$ & $15.53(43)$ & $13.97(40)$ & $15.52(32)$ & - \\
\hline $\mathrm{AUC}_{0-\text { inf }} /$ dose $(\mathrm{h} \cdot \mathrm{ng} / \mathrm{mL} / \mathrm{mg})$ & $15.96(45)$ & $14.39(4 \mid)$ & $16.03(32)$ & - \\
\hline
\end{tabular}

Note: ${ }^{\vee}$ Values expressed as median (minimum-maximum).

Abbreviations: $\mathrm{AUC}_{0 \text {-inf }}$ area under the concentration-time curve from time zero extrapolated to infinite time; $\mathrm{AUC}_{0-\text { inf }} / \mathrm{dose}, \mathrm{dose}-\mathrm{normalized} \mathrm{AUC}_{0-\text { inf }} ; \mathrm{AUC}_{0-\mathrm{t}} / \mathrm{dose}$, dose-normalized $\mathrm{AUC}_{0-\mathrm{t}} ; \mathrm{AUC}_{0-\mathrm{t}}$, area under the plasma concentration-time curve from time zero to last measurable time; $\mathrm{Cl}$, confidence interval; $\mathrm{CV}$, coefficient of variation; $C_{\text {max }}$, peak plasma concentration of eletriptan; $C_{\max } /$ dose, dose-normalized $C_{\max } ; \mathrm{HBr}$, hydrobormide; $\mathrm{PK}$, pharmacokinetics; $\mathrm{T}_{\max }$, time to reach $\mathrm{C}_{\max } ; \mathrm{t}_{\mathrm{I} / 2}$, elimination half-life. 

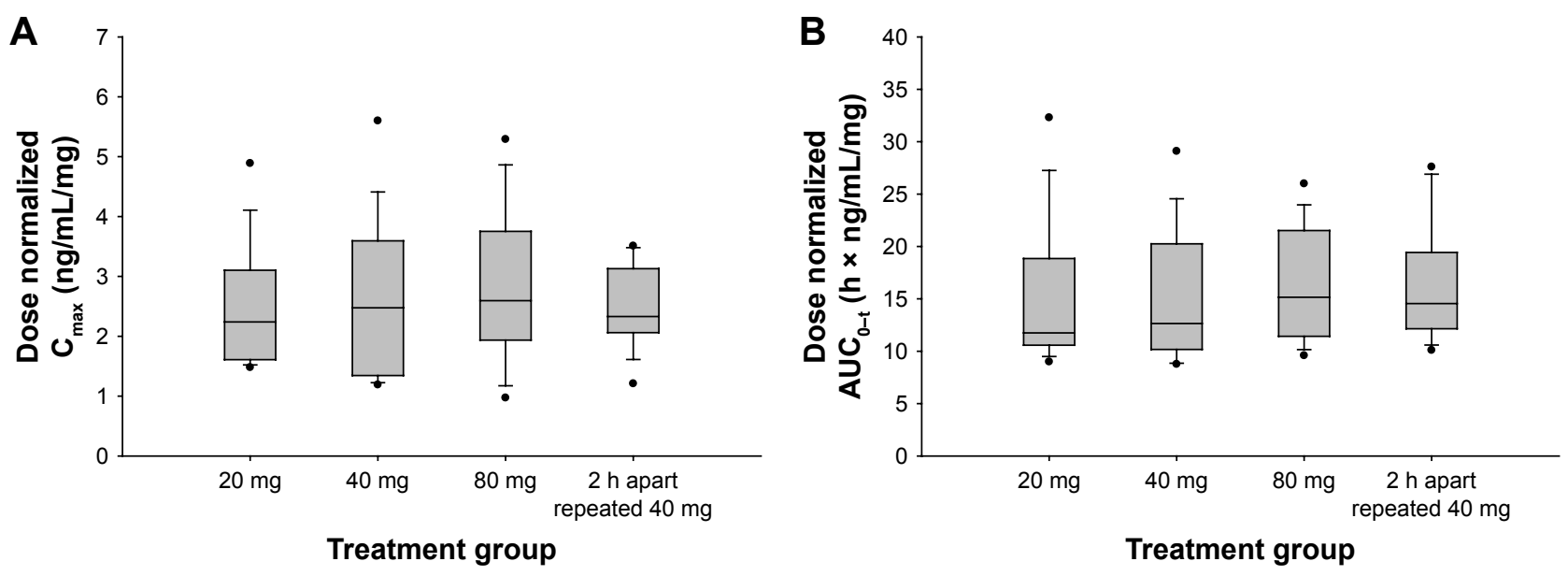

Figure 3 Dose-normalized pharmacokinetic parameters of eletriptan after single oral doses of eletriptan hydrobromide in healthy Korean subjects; (A) $C_{\text {max }}$ and (B) $\mathrm{AUC}_{0-\mathrm{i}}$.

Notes: The line across each box, the top edge, and the bottom edge represent the median, the first quartile, and the third quartile, respectively. The horizontal lines connected with the whiskers extending from the box denote the minimum and the maximum values, respectively. Solid circles $(\bullet)$ indicate outliers, defined as a value less than the first quartile minus 1.5 times interquartile range or a value greater than the third quartile plus 1.5 times interquartile range.

Abbreviations: $\mathrm{AUC}_{0-\mathrm{t}} ; \mathrm{AUC}_{0-\mathrm{t}}$, area under the plasma concentration-time curve from time zero to last measurable time; $\mathrm{C}_{\max }$, peak plasma concentration of eletriptan.

drug-related AEs were mild in intensity, and none of these led to the discontinuation of the study (Table 3). Throughout the study period, single oral doses of eletriptan $\mathrm{HBr} 20,40$, $80 \mathrm{mg}$, and two repeated doses of $40 \mathrm{mg} 2 \mathrm{~h}$ apart were well tolerated in all Korean subjects. There were no discrepancies between the dose groups in frequencies and severity of AEs.

When compared to the non-Korean subjects, Korean subjects did not exhibit any new adverse effects. Taking the

Table 2 The dose-normalized PK parameters of eletriptan following single oral doses of eletriptan $\mathrm{HBr}$ in Korean $(\mathrm{N}=48)$ and nonKorean $(\mathrm{N}=47)$ subjects

\begin{tabular}{|c|c|c|}
\hline \multirow[t]{2}{*}{ Parameters } & \multicolumn{2}{|c|}{$\begin{array}{l}\text { Geometric mean }[\% \mathrm{CV}] \\
(90 \% \mathrm{Cl})^{\mathrm{a}, \mathrm{b}}\end{array}$} \\
\hline & $\begin{array}{l}\text { Korean } \\
(N=48)^{c}\end{array}$ & $\begin{array}{l}\text { Non-Korean } \\
(\mathbf{N}=47)^{\mathrm{d}, \mathrm{e}}\end{array}$ \\
\hline $\begin{array}{l}\mathrm{C}_{\max } / \text { dose } \\
(\mathrm{ng} / \mathrm{mL} / \mathrm{mg})\end{array}$ & $\begin{array}{l}2.40[44.2] \\
(2.08-2.77)\end{array}$ & $\begin{array}{l}2.02[40.9] \\
(1.67-2.45)\end{array}$ \\
\hline $\mathrm{AUC}_{0-\mathrm{t}} /$ dose & 14.50 [38.6] & 14.18 [49.8] \\
\hline (h.ng/mL/mg) & $(12.78-16.46)$ & $(11.26-17.85)$ \\
\hline $\begin{array}{l}\text { AUC }_{0-\text { inf }} / \text { dose } \\
\text { (h.ng/mL/mg) }\end{array}$ & $\begin{array}{l}14.98[39.7] \\
(13.15-17.05)\end{array}$ & $\begin{array}{l}14.49[49.6] \\
(11.5 \mid-18.23)\end{array}$ \\
\hline
\end{tabular}

Notes: aCalculated by weighted average pooling method. 'Intra-CV for Korean, and total-CV for non-Korean. 'Single oral doses of 20, 40, $80 \mathrm{mg}$ eletriptan $\mathrm{HBr}$. 'Single oral doses of $30,60,90,120 \mathrm{mg}$ eletriptan $\mathrm{HBr}$. ${ }^{e}$ Data adapted with permission from Shah AK, Harris SC, Greenhalgh C, Morganroth J. The pharmacokinetics and safety of single escalating oral doses of eletriptan. J Clin Pharmacol. 2002;42(5):520-527. () 2002 John Wiley and Sons. ${ }^{9}$

Abbreviations: $\mathrm{AUC}_{0 \text {-inf }} /$ dose, dose-normalized area under the concentrationtime curve from time zero extrapolated to infinite time; $\mathrm{AUC}_{0-\mathrm{t}} / \mathrm{dose}$, dosenormalized area under the plasma concentration-time curve from time zero to last measurable time; $\mathrm{Cl}$, confidence interval; $\mathrm{CV}$, coefficient of variation; $\mathrm{C}_{\max } /$ dose, dose-normalized peak plasma concentration of eletriptan; $\mathrm{HBr}$, hydrobormide; PK, pharmacokinetics.
AEs and other tolerability parameters such as vital signs and physical examination into consideration, ${ }^{9}$ tolerability in the Korean study appeared to be similar to that observed in the non-Korean study.

\section{Discussion}

This study was designed for the assessment of PK characteristics and tolerability of eletriptan $\mathrm{HBr}$ in Korean subjects after the administration of the US-approved doses of 20, 40, and $80 \mathrm{mg}$. In addition, the PK characteristics of the repeated dose of $40 \mathrm{mg} 2 \mathrm{~h}$ apart were assessed. This is clinically important as only $70 \%$ of the migraine patients achieved headache relief $2 \mathrm{~h}$ after the single-dose administration of eletriptan $\mathrm{HBr} .{ }^{13,14}$ The effectiveness of eletriptan $\mathrm{HBr}$ in the treatment of headache recurrence for the $40 \mathrm{mg}$ dose has already been observed in migraine patients. ${ }^{15}$ For the achievement of balance and maximization of comparisons with the smallest number of subjects, Williams Design with four treatments, four sequences, and four periods was selected to assess the PK characteristics and tolerability of eletriptan $\mathrm{HBr}$ in Korean subjects.

The PK profiles of eletriptan $\mathrm{HBr}$ showed peaks with shoulders in 20 and $40 \mathrm{mg}$ treatment groups and double peaks in $80 \mathrm{mg}$ treatment group around $4 \mathrm{~h}$ after the oral dose (Figure 2). This phenomenon may have occurred owing to the enterohepatic recirculation of eletriptan, which is mainly eliminated via metabolism by the liver CYP enzymes ${ }^{10}$ and through bile acid secretion after food intake, which was done $4 \mathrm{~h}$ after dosing; eletriptan $\mathrm{HBr}$ undergoes extensive biliary excretion. ${ }^{16}$ The already absorbed 
Table 3 Summary of treatment-emergent AEs that occurred after single and $2 \mathrm{~h}$ apart repeated oral doses of eletriptan $\mathrm{HBr}$ in healthy Korean subjects $(\mathrm{N}=16)$

\begin{tabular}{|c|c|c|c|c|}
\hline & \multicolumn{4}{|l|}{ Treatment } \\
\hline & $20 \mathrm{mg}$ & $40 \mathrm{mg}$ & $80 \mathrm{mg}$ & $40 \mathrm{mg}$ repeated \\
\hline $\begin{array}{l}\text { Number of subjects with } \\
\text { at least one } A E^{a}\end{array}$ & I (6.25) & I (6.25) & $4(25)$ & $3(18.75)$ \\
\hline Number of AEs & 1 & 1 & 7 & 5 \\
\hline \multirow[t]{5}{*}{ Incidence of mild $A E^{b}$} & Nausea [I] & Nausea $[\mathrm{I}]$ & Nausea [I] & Oral mucosa erosion $[\mathrm{I}]$ \\
\hline & & & Oral mucosa erosion [I] & Musculoskeletal stiffness [I] \\
\hline & & & Fatigue $[I]$ & Headache $[I]$ \\
\hline & & & Headache [2] & Oropharyngeal discomfort [I] \\
\hline & & & Oropharyngeal discomfort [I] & \\
\hline Incidence of moderate $\mathrm{AE}$ & - & - & Chest discomfort $[\mathrm{I}]$ & Chest discomfort [I] \\
\hline
\end{tabular}

Notes: aData shown as number of subjects (\% of subjects). ${ }^{b}$ Data shown as incidence of AE [number of subjects with the incidence].

Abbreviations: $\mathrm{AE}$, adverse event; $\mathrm{HBr}$, hydrobormide.

eletriptan is reintroduced into the gastrointestinal tract via the bile. As a result, the systemic exposure of eletriptan rises. This reabsorption from the bile contributes toward the formation of shoulders and double-peaked characteristics of the PK profiles. ${ }^{17}$ Such PK characteristics were often observed in previous studies..$^{9,18}$

The point estimates of dose-normalized $\mathrm{C}_{\max }, \mathrm{AUC}_{0-\mathrm{t}}$, and $\mathrm{AUC}_{0 \text {-inf }}$ were also similar in Korean and non-Korean subjects after single oral doses of eletriptan $\mathrm{HBr}$ (Table 2). Sensitivity to ethnic differences evaluated in accordance with the International Conference on Harmonization E5 guideline, Appendix D, would be expected to be low. ${ }^{19}$ Low sensitivity to ethnic factors of eletriptan $\mathrm{HBr}$ was estimated using the known characteristics such as relatively high bioavailability, ${ }^{9}$ metabolism distributed among multiple pathways, ${ }^{10,20}$ and linear PK in previous non-Korean studies and the present Korean study. ${ }^{9,10,15}$ Currently, there is no evidence that the onset of migraine pattern differs in Korean and the non-Korean patients. In addition, no differences in dosage and corresponding effects have been reported in Korean and non-Korean subjects for other triptan drugs so far. ${ }^{21}$ The quantitative relationships between the exposure of eletriptan (PK) and the drug-driven effects (pharmacodynamics) observed in migraine patients have been well established in previous studies. ${ }^{6}$ Thus, we deduce that the clinical efficacy in Korean migraine patients will be similar to that in non-Korean patients at same dosage.

The most frequently reported AEs were nausea and headache, in the $20 \mathrm{mg}$ and $40 \mathrm{mg}$ single dose-groups, respectively, and chest discomfort from a single subject was the only moderate AE reported in $80 \mathrm{mg}$ single-dose and $40 \mathrm{mg}$ repeated-dose groups (Table 3). Based upon the absence of serious AEs, dose reductions or discontinuations due to reported AEs, eletriptan $\mathrm{HBr}$ was considered both safe and well tolerated after single administration within the dose range of $20-80 \mathrm{mg}$, as well as after repeated administration of $40 \mathrm{mg} 2 \mathrm{~h}$ apart in healthy male subjects.

In summary, PK and tolerability in Korean subjects were comparable to those in the non-Korean subjects after single and repeated doses of eletriptan $\mathrm{HBr}$. Although the present study has been performed in healthy male volunteers, the similar PK and tolerability profiles shown between the healthy and migraine patients in the previous non-Korean subject studies ${ }^{22}$ and known evidence of eletriptan PK being unaffected by sex ${ }^{22}$ suggests that different sex and patient status are factors unlikely to alter the conclusions reached from the healthy subjects in this study. From this evidence for low sensitivity to ethnic factors, dosage regimens identical to those for non-Korean patients may be suggested for Korean patients without further confirmatory study in Korean migraine patients.

\section{Conclusion}

Eletriptan $\mathrm{HBr}$ showed linear PK and was well tolerated in Korean subjects. The observed PK and tolerability were similar to those of non-Korean subjects. Therefore, we suggest that the same dosage regimen of eletriptan $\mathrm{HBr}$ may be recommended for Korean as well as non-Korean patients with migraine.

\section{Acknowledgments}

The first author (Yu Kyong Kim) received a scholarship from the BK21-plus education program provided by the National Research Foundation of Korea. This study was sponsored by Pfizer, Inc. The authors gratefully acknowledge the support of Ji-Young Lee, Pfizer, Inc., in manuscript coordination, and Hyungmi An, Seoul National University College of Medicine and Hospital, for statistical analyses. 


\section{Author contributions}

All authors contributed toward data analysis, drafting and critically revising the paper, gave final approval of the version to be published, and agree to be accountable for all aspects of the work.

\section{Disclosure}

Jeffrey Alderman is employed by Pfizer, Inc. The authors report no other conflicts of interest in this work.

\section{References}

1. Lipton RB, Stewart WF, von Korff M. Burden of migraine: societal costs and therapeutic opportunities. Neurology. 1997;48(3 Suppl 3):S4-S9.

2. Goodell H, Ostfeld AM, Pichler E, Wolff HG. Studies on headache; central versus peripheral action of ergotamine tartrate and its relevance to the therapy of migraine headache. AMA Arch Neurol Psychiatry. 1956;76(6):571-577.

3. Napier C, Stewart M, Melrose H, Hopkins B, McHarg A, Wallis R. Characterisation of the 5-HT receptor binding profile of eletriptan and kinetics of $[3 \mathrm{H}]$ eletriptan binding at human 5-HT1B and 5-HT1D receptors. Eur J Pharmacol. 1999;368(2-3):259-268.

4. Willems E, De Vries P, Heiligers JP, Saxena PR. Porcine carotid vascular effects of eletriptan (UK-116,044): a new 5-HT1B/1D receptor agonist with anti-migraine activity. Naunyn Schmiedebergs Arch Pharmacol. 1998;358(2):212-219.

5. Jhee SS, Shiovitz T, Crawford AW, Cutler NR. Pharmacokinetics and pharmacodynamics of the triptan antimigraine agents: a comparative review. Clin Pharmacokinet. 2001;40(3):189-205.

6. Diener HC. Eletriptan in migraine. Expert Rev Neurother. 2005; 5(1):43-53.

7. Garcia-Ramos G, MacGregor EA, Hilliard B, Bordini CA, Leston J, Hettiarachchi J. Comparative efficacy of eletriptan vs naratriptan in the acute treatment of migraine. Cephalalgia. 2003;23(9):869-876.

8. Steiner TJ, Diener HC, MacGregor EA, Schoenen J, Muirheads N, Sikes CR. Comparative efficacy of eletriptan and zolmitriptan in the acute treatment of migraine. Cephalalgia. 2003;23(10):942-952.

9. Shah AK, Harris SC, Greenhalgh C, Morganroth J. The pharmacokinetics and safety of single escalating oral doses of eletriptan. J Clin Pharmacol. 2002;42(5):520-527.

10. Milton KA, Scott NR, Allen MJ, et al. Pharmacokinetics, pharmacodynamics, and safety of the 5-HT(1B/1D) agonist eletriptan following intravenous and oral administration. J Clin Pharmacol. 2002;42(5): $528-539$.
11. World Medical Association. World Medical Association Declaration of Helsinki: ethical principles for medical research involving human subjects. JAMA. 2013;310(20):2191-2194.

12. Food and Drug Administration. Guidance for industry, E6 good clinical practice: consolidated guidance. Presented at International Conference on Harmonisation Good Clinical Practice. Federal Register. Vol 62, 1997:25691-25709.

13. Dodick DW. Triptan nonresponder studies: implications for clinical practice. Headache. 2005;45(2):156-162.

14. Tfelt-Hansen P, Edvinsson L. Pharmacokinetic and pharmacodynamic variability as possible causes for different drug responses in migraine. A comment. Cephalalgia. 2007;27(10):1091-1093.

15. Food and Drug Administration Center for Drug Evaluation and Research. Clinical Review of NDA Number 21-016, Relpax. In: US Food and Drug Administration Division of Neuropharmacological Drug Products. Maryland: Food and Drug Administration; 2002.

16. Food and Drug Administration Center for Drug Evaluation and Research. Pharmacology Review of NDA Number 21-016, Relpax. In: US Food and Drug Administration Division of Neuropharmacological Drug Products. Maryland: Food and Drug Administration; 1999.

17. Davies NM, Takemoto JK, Brocks DR, Yanez JA. Multiple peaking phenomena in pharmacokinetic disposition. Clin Pharmacokinet. 2010; 49(6):351-377.

18. Shah AK, Laboy-Goral L, Scott N, Morse T, Apseloff G. Pharmacokinetics and safety of oral eletriptan during different phases of the menstrual cycle in healthy volunteers. J Clin Pharmacol. 2001;41(12): 1339-1344.

19. ICH Harmonised Tripartite Guideline. Ethinic Factors in the Acceptability of Foreign Clinical Data E5 (R1). Poster presented at: International Conference on Harmonisation of Technical Requirements for Registration of Pharmaceuticals for Human Use. ICH Expert Working Group; 1998:1-13.

20. Evans DC, O’Connor D, Lake BG, Evers R, Allen C, Hargreaves R. Eletriptan metabolism by human hepatic CYP450 enzymes and transport by human P-glycoprotein. Drug Metab Dispos. 2003;31(7):861-869.

21. Morillo LE. Migraine headache in adults. Clin Evid. 2004;65(11): 1696-1719.

22. Relpax $(\mathrm{R})$ [drug label]. New York: Pfizer Inc; 2013. Available from: http:/www.accessdata.fda.gov/drugsatfda_docs/label/2013/021016s0 21s023s024s027lbl.pdf. Accessed July 13, 2016.

\section{Publish your work in this journal}

Drug Design, Development and Therapy is an international, peerreviewed open-access journal that spans the spectrum of drug design and development through to clinical applications. Clinical outcomes, patient safety, and programs for the development and effective, safe, and sustained use of medicines are the features of the journal, which

\section{Dovepress}

has also been accepted for indexing on PubMed Central. The manuscript management system is completely online and includes a very quick and fair peer-review system, which is all easy to use. Visit http://www.dovepress.com/testimonials.php to read real quotes from published authors. 